\title{
Social Determinants Do Not Determine Me
}

\author{
Haleigh Prather* MHS \\ Oregon Health \& Science University, Portland, OR, USA \\ *Corresponding author: Haleigh Prather, Oregon Health \& Science 3181 S.W. Sam Jackson Park Road, Portland, OR 97239-3098, USA
}

Received: October 19, 2021; Accepted: November 09, 2021; Published: November 30, 2021

\begin{abstract}
Abbreviations: AFDC: Aid to Families with Dependent Children, WIC: Women, Infants and Children

The apartment complex in which I lived growing up was called, "The Bellagio," and its name was written in golden, cursive letters on the exterior of the building. As a child I always thought this name sounded so elegant, like a ballet dance step. But if you unlocked the front door, you would notice the dingy grey carpet, the cracked and yellowing blinds, and the faint stench of tobacco emanating from the apartment of the old man who lived in the unit below. It wasn't elegant, but to my single mother and me, it was home.
\end{abstract}

My mother frequently tells me, "I didn't want us to be another statistic." What she meant was that as young, Hispanic women who lived below the poverty line, society expected our lives would amount to very little. These multidimensional identities - female, poor, Hispanic - had placed us at the front doorstep of intergenerational poverty, which we would have to defy serious odds to overcome. In medicine, we call these obstacles the "social determinants of health," which we use to predict and explain health outcomes. But these issues do more than impact risk of disease: they extend their roots into class, career, and community. From the air quality of a neighborhood to the processed sugars in affordable food, they act as the cloudy weather that influences how readily the blossoms of life can bloom. My reflections on my childhood inform my understanding of how these social determinants both did and did not "determine" my life and provide a unique opportunity to serve and advocate for poor families, Hispanic families, and especially those families led by single parents.

Recent data demonstrates that families headed by single mothers are most vulnerable to poverty $[1,2]$ and that their children face greater obstacles related to educational achievement and adjustment in school [3]. Indeed, for many years my mother and I relied on government assistance programs, including Aid to Families with Dependent Children (AFDC), Women, Infants and Children (WIC), and Medicaid, which funded the bare necessities required for child rearing. I remember spending afternoons in a grey government building playing with communal toys that had been well-loved by many children before me while my mother secured diapers and milk for another week.

Despite these barriers, I was fortunate to be among the $6.8 \%$ of Hispanic applicants that are accepted to medical school $[4,5]$ a percentage that shrinks even further if you control for class, gender, and single-parent households. This felt strange to me, given that almost $18.5 \%$ of the American population is Hispanic or Latino, a number that continues to rise [6]. Together, these statistics suggest a severe underrepresentation of Hispanic medical school applicants and matriculants relative to the age-adjusted US population [5].

I felt the effects of my minority status almost immediately after starting medical school. During my first week, a group of peers were recounting their favorite travel stories. They took turns sharing tales of Icelandic landscapes and tropical paradises. In that moment, I realized I was one of very few to not have had those same kinds of experiences. My only travel history was my semester abroad, and I had taken out extra loans just to afford the plane ticket. It felt like no one else in my medical school cohort had a background like mine. The voice in my head told me that if you're standing in a space where no one relates to you, that's an unspoken affirmation that maybe you don't belong there. This became a pattern, as I was reminded again and again that my peers and I had very different upbringings, leaving me searching for a personal connection to medicine.

Despite these peer interactions that colored my early medical school experience, I found that in clinical practice, many of my patients did share in my life experiences. It felt familiar interacting with patients who lived in poor areas reminiscent of my own neighborhood, or who were children of single parents. These patients remind me that I belong in medicine, and that my visibility and perspective are important. All patients can benefit from encountering physicians that look like them and relate to their background. These relationships can decrease subconscious bias [7], bridge gaps in health care delivery, and build a deeper bond of trust. Interactions with this patient population remind me that I represent the children of poor, Hispanic, single-parent households, and my personal connection to medicine is found in serving them.

One story from my clinical experiences that has remained with me is an encounter I had on the Mother-Baby Unit during my pediatric rotation. We were rounding on a one-day-old Hispanic baby girl whose mother was a single parent. After asking the mother about whether she needed financial assistance, the attending physician handed her a pamphlet on WIC, then wished her a genuine "good luck" before we hurried on to see the next family. As we left, I noticed that the mother had started to cry.

I couldn't stop thinking about this mom and her child, and how closely this family dynamic mirrored the experience of my own mother. Alone and at the starting line of single parenthood, had someone once 
handed my mom a pamphlet on WIC? I couldn't shake the need to go back to her room and take some time to initiate a heartfelt conversation. I rehearsed the different ways I could tell her that I understood her situation first-hand. I wanted her to know that single parenthood didn't have to define what her and her daughter's lives could be, and that there was every possibility that her daughter could accomplish anything she wanted, even end up in medical school someday.

As we finished rounding, I walked back to her room and stood outside the door. I started to doubt myself. I wondered if this conversation was inappropriate or unprofessional, or if I was somehow overstepping my boundaries as a medical student. I lingered outside her room for a few minutes, and when I finally walked in, she was asleep. I wish I could say that I came back later, spoke with her, and made a meaningful impact. But instead, I let the fear of repercussions get the best of me. Looking back, that experience taught me that if I want to make a difference in the lives of my patients, I must be brave and bold, as well as confident that these conversations and visibility are needed and necessary.

While I enjoy working with my peers to provide quality care, my sense of community is fulfilled by working with underserved patients. I am motivated to share my stories and explore the ways in which medical professionals can better advocate for and communicate with them. With these efforts, I strengthen my personal value system, bridge gaps in health equity, and pay homage to my upbringing. I am proud to be an example of how although "social determinants" may have an impact on life, they do not automatically determine worth, value, or achievement.

\section{References}

1. McLanahan S, Percheski C (2008) Family structure and the reproduction of inequalities. Annu Rev Sociol 34: 257-276.

2. Damaske S, Bratter JL, Frech A (2017) Single mother families and employment, race, and poverty in changing economic times. Social science research 62: 120-133. [crossref]

3. Carlson MJ, Corcoran ME (2001) Family structure and children's behavioral and cognitive outcomes. Journal of marriage and family 63: 779-792.

4. https://www.aamc.org/data-reports/students-residents/interactive-data/2020-factsapplicants-and-matriculants-data Accessed July 19th, 2021.

5. Lett LA, Murdock HM, Orji WU, Aysola J, Sebro R (2019) Trends in racial/ ethnic representation among US medical students. JAMA network open 2: e1910490-e1910490. [crossref]

6. United States Census Bureau: QuickFacts. 2019. https://www.census.gov/quickfacts/ fact/table/US/RHI725219. Accessed June $16^{\text {th }}, 2021$.

7. Bean MG, Stone J, Badger TA, Focella ES, Moskowitz GB (2013) Evidence of nonconscious stereotyping of Hispanic patients by nursing and medical students. Nursing research 62: 362-367. [crossref] 